С. Ф. Чалий, В. О. Лещинський, І. О. Лещинська

Харківський національний університет радіоелектроніки, Харків, Україна

\title{
УЗГОДЖЕННЯ ПОЯСНЕННЯ В ІНТЕЛЕКТУАЛЬНІЙ ІНФОРМАЦІЙНІЙ СИСТЕМІ З БАЗОВИМИ ЗНАННЯМИ ЩОДО ПРЕДМЕТНОЇ ОБЛАСТІ
}

\begin{abstract}
Предметом вивчення в статті $є$ процеси побудови пояснень щодо запропонованих інтелектуальною інформаційною системою рішень. Метою $є$ розробка методу узгодження пояснень в інтелектуальній інформаційній системі з урахуванням обмежень, які визначаються базовими знаннями щодо об'єктів та процесів у предметної області. Завдання: структуризація процесу побудови пояснень з урахуванням обмежень, представлених знаннями щодо предметної області; визначення аспектів узгодження пояснення; розробка методу узгодження знань щодо пояснення та предметної області. Використовуваними підходами є: підходи до побудови пояснень, підходи до узгодження знань. Отримані наступні результати. Виконано структуризацію процесу побудови пояснень 3 урахуванням етапу узгодження знань. Виділено аспекти узгодження знань пояснення із вхідними даними в сенсі використання даних для тлумачення, із отриманим інтелектуальною інформаційною системою рішенням в сенсі узгодження з задачами користувача, а також із знаннями предметної області в сенсі обмежень для використання пояснення. Запропоновано метод узгодження пояснення із знаннями щодо предметної області. Висновки. Наукова новизна отриманих результатів полягає в наступному. Запропоновано метод узгодження пояснення із базовими знаннями щодо об'єктів та процесів у предметної області. Метод передбачає ітеративне виконання послідовності узгодження даних щодо процесу прийняття рішень в інтелектуальній системі із знаннями, що описують предметну область, перевірку узгодженості розробленого пояснення із множиною знань щодо предметної області, а також узгодження пояснення з результуючим рішенням інтелектуальної інформаційної системи. В практичному аспекті метод орієнтований на формування підмножини пояснень, що не протирічать базовим 3 знанням щодо предметної області. Пояснення у складі цієї множини у подальшому можуть бути упорядковані за критерієм ефективності, з урахуванням особливостей задач, для вирішення яких призначені сформовані інтелектуальною системою рішення.
\end{abstract}

Ключов і слов а : знання щодо предметної області; узгодженість знань; інтелектуальна інформаційна система; рекомендації; пояснення, патерни пояснень.

\section{Вступ}

Інтелектуальні інформаційні системи (IIC) застосовуються при вирішення неструктурованих або частково структурованих задач на основі поєднання формальних та евристичних підходів. Тому процес отримання рішення в IIC є закритим для користувача, що зменшує довіру останнього до отриманих результатів. Для того, щоб підвищити довіру користувача та спонукати його до використання результатів роботи IIC, використовують пояснення [1]. Пояснення дає можливість користувачеві отримати відповідь на питання «Чому було отримано саме цей результат?» або «Чи можна успішно імплементувати запропонований результат при вирішенні задач користувача?».

Наприклад, пояснення в рекомендаційні системі можуть показувати, що інші користувачі успішно використали рекомендований продукт або послугу. Пояснення є обгрунтуванням для користувача рішення, представленого інтелектуальною інформаційною системою, оскільки воно формує причиннонаслідкові зв'язки між отриманим результатом та поточними задачами споживача $[2,3]$.

Побудова пояснення полягає у формуванні спрощеного опису процесу вирішення задачі у інтелектуальній системі $з$ тим, щоб користувач міг, базуючись на знаннях щодо предметної області, сформувати для себе причини отриманого інтелектуальною системою рішення. Пояснення відображає приховані шаблони та закономірності у процесі отри- мання рішення інтелектуальною системою. Тому задача побудови пояснення $\epsilon$ окремим випадком задачі виявлення патернів. Інтерпретація цих патернів виконується користувачами IIC з використанням базових знань щодо предметної області. Базові знання характеризують об'єкти та процеси, що протікають у визначеній предметній області.

Такі знання дають можливість інтерпретувати та використовувати патерни пояснень. Частково такі знання $\epsilon$ неявними, оскільки вони задають зв'язок між відомими 3 практики індивідуума фактами, подіями, процедурами та представлені не в документах, а в пам'яті людини [4]. Таким чином, побудова патернів пояснень потребує узгодження знань у складі пояснень із базовими знаннями предметної області, що і визначає актуальність теми даного дослідження.

Методи представлення пояснень в IIC використовують ідеї витлумачень за допомогою експертних правил або прецедентів [5]. Підходи до використання специфічних для предметної області, а також темпоральних знань при вирішенні задачі побудови пояснень в рекомендаційних системах розглядались в роботах [6-10].

Для рекомендаційних систем знання про предметну область містять характеристики користувачів та рекомендованих предметів.

Темпоральні знання описують зміни вподобань користувачів з часом. Характер цих знань визначає спосіб побудови інтерфейсу для представлення пояснень користувачеві [11]. 
Узагальнений підхід до узгодження знань представлено в роботах [12]. Сутність даного підходу полягає у виділенні підмножин узгоджених та неузгоджених залежностей. Елементи першої підмножини попарно пов'язані відношенням узгодження. При побудові пояснень в якості такого відношення виступає відношення пояснення. Для пари елементів знань, в якій один із елементів належить до множини неузгоджених знань, $€$ істинним відношення неузгодження знань.

Наприклад, такі знання можуть бути несумісними із базовими знанням щодо предметної області. Тобто дані відношення $є$ обмеженнями, що визначають порядок відбору елементу знань до першої або другої підмножини [13].

Ключова умова формування множини узгоджених знань полягає у формальному визначенні відношення узгодження $[14,15]$. Підходи до визначення даного відношення значною мірою залежать від аспекту, в якому розглядаються множини узгоджених та неузгоджених знань. Зокрема, у темпоральному аспекті узгоджені знання мають визначати однакову зміну властивостей об'єктів та процесів у предметній області з часом.

Наприклад, зростання або зменшення продажів в системі електронної комерції. У технічному аспекті пояснення показує переваги від використання отриманих результатів для вирішення задач користувача.

Тобто такі підходи дають можливість на основі пояснення порівняти існуючі рішення та нові рішення, що запропонувала інтелектуальна інформаційна система. Однак вони не задають обмеження на пояснення. Використання обмежень дозволить відкинути ті патерни, що суперечать поточному стану або динаміці стану предметної області.

Задача визначення таких обмежень на основі узгодження знань у складі пояснення та базових знань щодо предметної області потребує свого вирішення.

Метою статті $\boldsymbol{\epsilon}$ розробка методу узгодження пояснень в інтелектуальній інформаційній системі 3 урахуванням обмежень, що визначаються базовими знаннями щодо об'єктів та процесів у предметної області.

Для досягнення поставленої мети вирішуються такі задачі:

- структуризація процесу побудови пояснень 3 урахуванням обмежень знань щодо предметної області;

- визначення аспектів узгодження пояснення;

- розробка методу узгодження знань щодо пояснення та предметної області.

\section{Структуризація процесу побудови пояснень $з$ узгодженням знань}

Традиційний процес виявлення патернів передбачає побудову елементів знань на основі виявлення залежностей в даних [16].

Побудова патернів пояснень потребує додаткового узгодження знань. Такий процес включає в себе в наступні етапи (рис. 1):
- попередня обробка даних;

- формування множини можливих патернів пояснення;

- пост-обробка: узгодження пояснень;

- вибір результуючого пояснення.

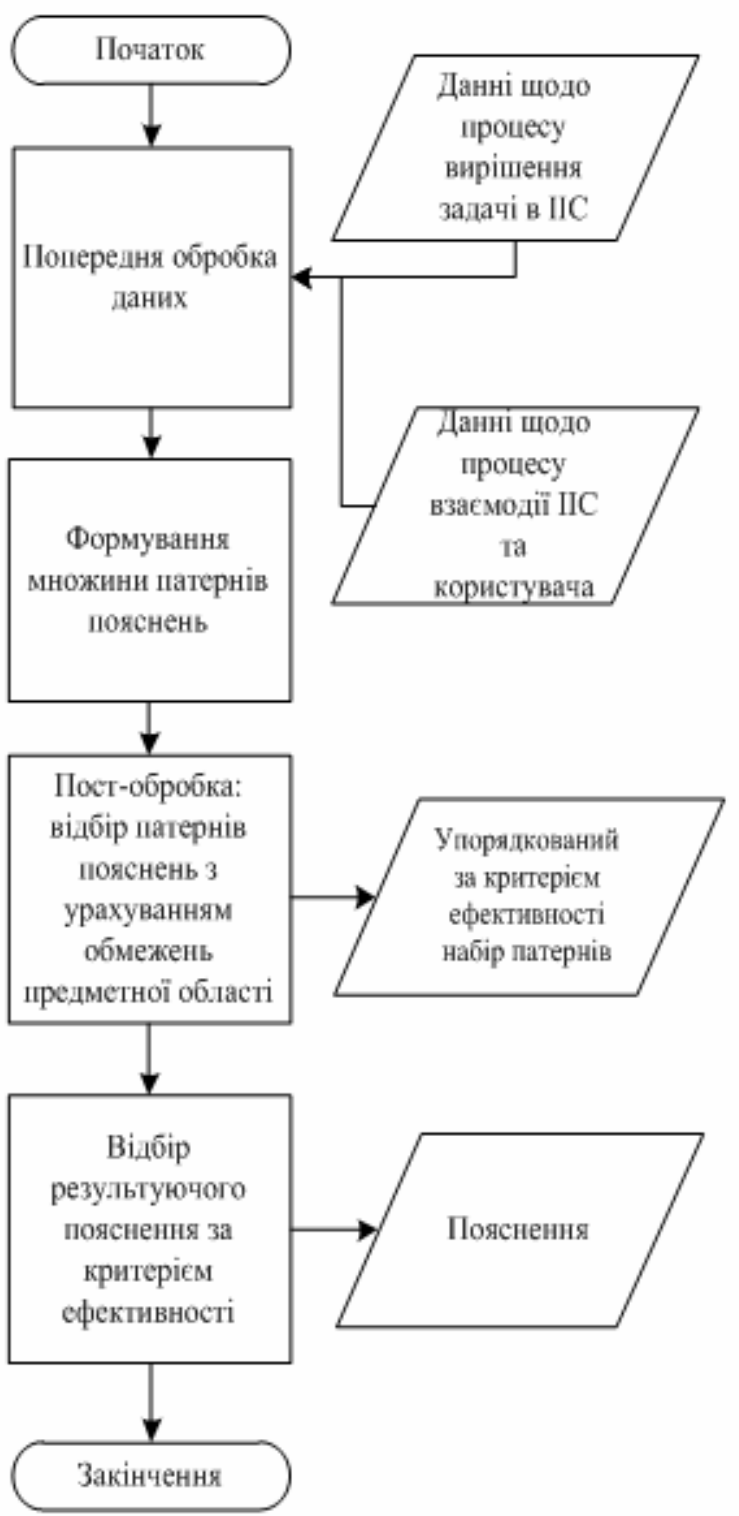

Рис. 1. Процес побудови пояснень в IIC

На першому етапі виконується фільтрація вхідних даних, що будуть використані для побудови пояснення.

На другому етапі проводиться виявлення набору патернів, що відображають різні закономірності процесу отримання рішення. Такі патерни можуть бути отримані з набору даних, що описує роботу інтелектуальної системи або процес іiї взаємодії 3 користувачами.

На третьому етапі множина отриманих патернів узгоджується, фільтрується та упорядковується. Фільтрація та упорядкування відбувається, відповідно, з урахуванням обмежень та інтегральної оцінки патернів.

Обмеження задають узгодженість знань патерну із знаннями щодо предметної області. 
Показник інтегральної оцінка патернів може враховувати особливості предметної області або можливості застосування пояснення.

В першому випадку показник формується в залежності від задачі, яку вирішує інтелектуальна система.

В другому випадку в якості інтегрального показника може виступати ефективність імплементації пояснення. Остання визначає ймовірність використання пояснення при вирішенні задач користувача.

Наприклад, для рекомендаційної системи ймовірнісний показник поточного пояснення відображає ймовірність того, що користувач вибере саме той товар, для якого було сформовано пояснення.

\section{Узгодження пояснення у аспектах знань, даних та рішення IIC}

Пояснення, що формується у відповідності до представленого в попередньому підрозділі процесу побудови пояснень, має такі властивості (рис. 2):

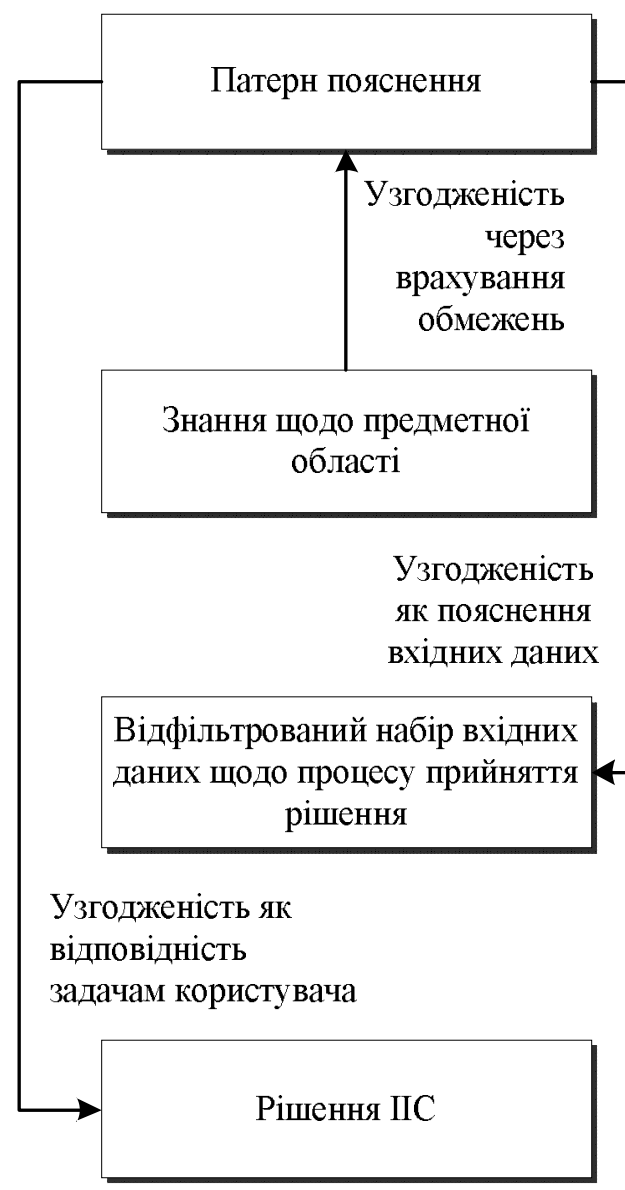

Рис. 2. Узгодження пояснення в IIC

- спрощене відображення послідовності прийняття рішення в інтелектуальній інформаційній системі;

- зрозумілість для користувача інтелектуальної інформаційної системи в сенсі відсутності протиріч із знаннями щодо предметної області;

- узгодженість із вхідними даними щодо процесу прийняття рішення або взаємодії із користувачем в сенсі їх тлумачення;
- узгодженість із задачами користувача (тобто у технічному аспекті).

Модель пояснення із наведеними властивостями має такі структурні особливості, які є суттєвими для методу узгодження пояснень:

- патерни задовольняють обмеженням узгодженості із вхідними даними та знаннями щодо предметної області;

- узгодженість патерну пояснення із отриманим інформаційною системою результатом та знаннями предметної області [17].

\section{Метод узгодження пояснень із базовими знаннями щодо предметної області}

Розроблений метод узгодження пояснень базується на ідеї дедуктивного уточнення та узгодження знань.

Даний метод передбачає інтерактивне коригування множин знань та даних 3 урахуванням їх відповідності результату роботи інформаційної системи та поясненню щодо цього результату. Тобто знання щодо предметної області можуть мати протиріччя і також можуть не відповідати задачам користувача. При реалізації методу такі знання видаляються із подальшого розгляду.

Результатом методу є множини знань та пояснень які є узгодженими між собою. В подальшому процесі відбору результуючого пояснення множина узгоджених знань може бути використана для вибору із набору пояснень із однаковими або близькими показниками ефективності.

Метод містить такі етапи.

Eman 1. Узгодження даних із процесу прийняття рішення в інтелектуальній інформаційній системі з знаннями щодо предметної області.

На даному етапі відбираються лише ті знання щодо предметної області, які використовують дані із вхідного набору для формування пояснень.

Крок 1.1. Перевірка узгодженості знань 3 предметної області $B$ та поточних даних $d \in D$ щодо процесу прийняття рішення в інтелектуальній інформаційній системі.

Дана перевірка встановлює можливість використання базових знань щодо об'єктів та процесів у предметній області у випадку її опису змінними та їх значеннями iз $d$. Кожен елемент $b$ знань про предметну область має бути істинними (не мати протиріч) у моделі предметної області, що представлена сукупністю знань $B$ :

$$
(\forall b) B, d \mid=b \text {. }
$$

Згідно (1) формалізовані залежності щодо поведінки предметної області мають виконуватись для вхідних даних $d$.

Якщо дана умова виконується, то дані щодо процесу прийняття рішення відповідають системі знань про предметну область і відбувається перехід до етапу 2.

В противному випадку виконується крок 1.2. 
Набір знань про предметну область частково залежить від потреб користувача IIC. Тому він може бути уточнений в залежності від результату роботи інтелектуальної інформаційної системи.

Крок 1.2. Уточнення знань щодо предметної області у відповідності до отриманого IIC рішення.

На даному кроці склад множини $B$ коригується таким чином, щоб умова (1) виконувалась для кожного елементу знань:

$$
B=\{b:(\forall b) B, d \mid=b\} .
$$

Крок 1.3. Узгодження знань із підмножини $B$ із результатом $r$ роботи IIC. На даному кроці перевіряється умова:

$$
B \mid=r .
$$

Згідно (3), всі елементи знань (наприклад, правила) мають відповідати результату $r$, не мати 3 ним протиріч. Тобто результат $r$ відповідає моделі предметної області, представленої сукупністю знань $B$.

Наприклад, в рекомендаційній системі знання про предметну область можуть визначати умови використання товару (професійний, побутовий). Процес побудови рекомендацій враховує інтереси користувача.

Такі інтереси визначаються на основі аналізу його минулих покупок, а також покупок схожих на нього за поведінкою користувачів. Тому у випадку наявності базових знань про те, що користувач цікавиться професійним обладнанням, узгоджена результуюча рекомендація має містити товари 3 професійними характеристиками.

При виконанні умови відбувається перехід до етапу 2. У випадку неузгодженості, якщо умова (3) не виконується, то результат IIC недоцільно пояснювати з використанням наявних базових знань. Робота методу на цьому кроці завершується.

Eman 2. Узгодження пояснення $e \in E$ iз знаннями щодо предметної області.

Крок 2.1 Перевірка істинність пояснення для поточного стану процесів у предметної області, що представлений набором даних $d$ :

$$
B, d \mid=e \text {. }
$$

Згідно (4), пояснення $e$ має відповідати (бути істинним) в рамках моделі знань $B$ для стану об'єктів та предметів $d$.

Якщо умова (4) не виконується, то це означає, що спрощений опис процесу прийняття рішення в IIC не використовує ряд елементів вхідного набору даних. Тому при узгодженні ці елементи доцільно видалити із множини $d$.

Крок 2.2. Уточнення набору $d$.

Даний крок виконується у випадку невиконання умови (4). Результуюча множина $d$ містить елементи $d_{i}$, для яких виконується умова:

$$
d=\left\{d_{i}:(\forall i) B, d_{i} \mid=e\right\}
$$

Eman 3. Узгодження пояснення з результатом, отриманим IIC.

На даному етапі перевіряється істинність результату у моделі пояснення, узгодженої із знаннями про предметну область 3 урахуванням іiі поточного стану.

$$
e \wedge(B, d) \mid=r
$$

Невиконання даної умови свідчить про порушення властивості транзитивності для відношення узгодження між знаннями, даними та результатом. Причинами такого порушення можуть бути зміни у складі множин $B$ та $d$ внаслідок уточнення знань (2) або уточнення даних (5). Відповідно, у випадку невиконання умови (6) відбувається перехід на етап 1 для подальшого уточнення знань. У випадку неможливості подальшого узгодження знань метод завершує свою роботу.

У випадку, якщо умова (6) виконується, то пояснення $є$ узгодженим із знанням щодо предметної області.

Результат виконання методу в подальшому використовується у процесі формування пояснень.

\section{Висновки}

Розглянуто проблему узгодження знань при побудові патернів пояснень. Дана проблема виникає при формуванні набору патернів для тлумачення отриманого інтелектуальною інформаційною системою результату.

При виборі фінального пояснення із існуючого набору необхідно враховувати відповідність пояснення знанням щодо предметної області. Такі знання виступають в ролі обмежень, що дають можливість виключити неузгоджені пояснення, які не мають практичного сенсу для споживача.

Виконано структуризацію процесу побудови пояснень 3 урахуванням етапу узгодження знань.

Виділено аспекти узгодження знань пояснення iз вхідними даними в сенсі тлумачення цих даних, iз результатом роботи інтелектуальної інформаційної системи в сенсі узгодження з задачами користувача, а також із знаннями предметної області в сенсі необхідних та достатніх умов використання пояснення.

Запропоновано метод узгодження пояснення із знаннями щодо предметної області. Метод передбачає перевірку можливості отримання пояснення 3 використанням даних 3 процесу прийняття рішень, узгодженого із знаннями щодо предметної області, перевірку узгодженості пояснення із знаннями щодо предметної області, а також узгодження результату роботи інтелектуальної системи 3 поясненням.

В практичному плані метод дає можливість сформувати підмножину допустимих пояснень, що не має протиріч із знаннями щодо предметної області. Фінальне пояснення може бути вибрано із цієї підмножини за критерієм ефективності, що враховує особливості задач, які вирішує користувач інтелектуальної інформаційної системи. 


\section{REFERENCES}

1. Miller T. (2019). Explanation in artificial intelligence: Insights from the social sciences. Artificial Intelligence, 267, pp. 1-38. DOI: https://doi.org/10.1016/j.artint.2018.07.007.

2. Tsai C., Brusilovsky P. (2019). Explaining recommendations in an interactive hybrid social recommender. Proceedings of the 24th International Conference on Intelligent User Interfaces, pp. 391-396.

3. Dominguez V., Messina P., Donoso-Guzmán I., Parra D. (2019). The effect of explanations and algorithmic accuracy on visual recommender systems of artistic images. Proceedings of the 24th International Conference on Intelligent User Interfaces (IUI '19), pp. 408-416.

4. Wooley, B. A. (1998). Explanation component of software system. Crossroads, 5(1), pp. 24-28.

5. Cunningham P., Doyle D., Loughrey J. (2003). An evaluation of the usefulness of case-based reasoning explanation. Proceedings of the International Conference on Case-Based Reasoning, Trondheim, Springer, pp. 122-130.

6. Cleger S., Fernбndez-Luna J., F Huete J. Learning from explanations in recommender systems. Information Sciences, 2014, 287, pp. 90-108.

7. Chalyi S., Leshchynskyi V., Leshchynska I. (2019). Method of forming recommendations using temporal constraints in a situation of cyclic cold start of the recommender system. EUREKA: Physics and Engineering, 4, pp. 34-40. DOI: $10.21303 / 2461-4262.2019 .00952$.

8. Чалий С.Ф., Лещинський В.О., Лещинська І.О. (2019). Моделювання пояснень щодо рекомендованого переліку об’єктів з урахуванням темпорального аспекту вибору користувача. Системи управління, навігації та зв'язку, 6 (58), 97-101.

9. Chalyi, S., Leshchynskyi, V. (2020). Method of constructing explanations for recommender systems based on the temporal dynamics of user preferences. EUREKA: Physics and Engineering, 3, 43-50. DOI: 10.21303/2461-4262.2020.001228.

10. Cleger S., Fernбndez-Luna J., F Huete J. (2014). Learning from explanations in recommender systems. Information Sciences, 287, pp. 90-108.

11. Daher J, Brun A., Boyer A. A. (2017). Review on Explanations in Recommender Systems. Technical Report. LORIA Université de Lorraine, $26 \mathrm{p}$.

12. Thagard P. (2007). Coherence, truth, and the development of scientific knowledge. Philosophy of Science, 74, pp. 28-47.

13. Thagard P. (2004). Causal inference in legal decision making: Explanatory coherence vs. Bayesian networks. Applied Artificial Intelligence, 18, pp. 231-249.

14. Thagard P., Verbeurgt K. (1998). Coherence as constraint satisfaction. Cognitive Science, 22, pp. 1-24.

15. Thagard P. (2010). Causal inference in legal decision making: explanatory coherence vs. Bayesian networks. Applied Artificial Intelligence, 18:3-4, 231-249. DOI: https://doi.org/10.1080/08839510490279861.

16. Fayyad, U., Piatetsky-Shapiro, G., and Smyth, P. (1996). From Data Mining to Knowledge Discovery in Databases. AI magazine, 17(3), 37.

17. Чалий С. Ф., Лещинський В. О., Лещинська I. О. (2020). Модель пояснення в інтелектуальній інформаційній системі на основі концепції узгодженості знань. Вісник Національного технічного університету "ХПІ". Сер. : Системний аналіз, управління та інформаційні технології, 1 (3), 19-23.

Received (Надійшла) 06.01.2021

Accepted for publication (Прийнята до друку) 17.02.2021

\section{Coordinating the explanation in the intellectual information system with the background knowledge}

S. Chalyi, V. Leshchynskyi, I. Leshchynska

Abstract. The subject matter of the article is the processes of constructing explanations for the solutions proposed by the intelligent information system. The goal is to develop a method for coordinating explanations in an intelligent information system, taking into account the constraints that are determined by basic knowledge about objects and processes in the subject area. Tasks: structuring the process of constructing explanations, taking into account the limitations in the form of knowledge about the subject area; highlighting the aspects of the agreement of the explanation; development of a method for harmonizing knowledge regarding the explanation and the subject area. The approaches used are: approaches to constructing explanations, approaches to harmonizing knowledge. The following results were obtained. The structuring of the process of constructing explanations was carried out, taking into account the stage of knowledge coordination. The aspects of the coordination of the knowledge of the explanation with the input data in the sense of using data for interpretation, with the solution obtained by the intelligent information system in the sense of matching with the user's tasks, as well as with the knowledge of the subject area in the sense of restrictions for the use of the explanation, are highlighted. A method for reconciling the explanation with knowledge about the subject area is proposed. Conclusions. The scientific novelty of the results obtained is as follows. A method for matching the explanation with basic knowledge about objects and processes in the subject area is proposed. The method provides for iterative execution of the sequence of reconciliation of data on the decision-making process in an intelligent system with knowledge describing the subject area, checking the consistency of the developed explanation with a lot of knowledge about the subject area, as well as reconciling the explanation with the resulting solution of the intelligent information system. In practical terms, the method is focused on the formation of a subset of explanations, does not contradict the basic one with knowledge of the subject area. The explanation in the composition of this set can be further ordered according to the criterion of efficiency, taking into account the peculiarities of the tasks for the solution of which the solutions are formed by the intelligent system.

Keywords: background knowledge; consistency of knowledge; intelligent information system; explanations, explanation patterns. 